\title{
Predictors of real-life mobility in community-dwelling older adults: an exploration based on a comprehensive framework for analyzing mobility
}

Eleftheria Giannouli ${ }^{1 *}$ (D) Michelle Pasquale Fillekes ${ }^{2,3}$, Sabato Mellone ${ }^{4}$, Robert Weibel ${ }^{3}$, Otmar Bock ${ }^{5}$ and Wiebren Zijlstra ${ }^{1}$

\begin{abstract}
Background: Reduced mobility is associated with a plethora of adverse outcomes. To support older adults in maintaining their independence, it first is important to have deeper knowledge of factors that impact on their mobility. Based on a framework that encompasses demographical, environmental, physical, cognitive, psychological and social domains, this study explores predictors of different aspects of real-life mobility in community-dwelling older adults.

Methods: Data were obtained in two study waves with a total sample of $n=154$. Real-life mobility (physical activity-based mobility and life-space mobility) was assessed over one week using smartphones. Active and gait time and number of steps were calculated from inertial sensor data, and life-space area, total distance, and action range were calculated from GPS data. Demographic measures included age, gender and education. Physical functioning was assessed based on measures of cardiovascular fitness, leg and handgrip strength, balance and gait function; cognitive functioning was assessed based on measures of attention and executive function. Psychological and social assessments included measures of self-efficacy, depression, rigidity, arousal, and loneliness, sociableness, perceived help availability, perceived ageism and social networks. Maximum temperature was used to assess weather conditions on monitoring days.

Results: Multiple regression analyses indicated just physical and psychological measures accounted for significant but rather low proportions of variance (5-30\%) in real-life mobility. Strength measures were retained in most of the regression models. Cognitive and social measures did not remain as significant predictors in any of the models.

Conclusions: In older adults without mobility limitations, real-life mobility was associated primarily with measures of physical functioning. Psychological functioning also seemed to play a role for real-life mobility, though the associations were more pronounced for physical activity-based mobility than life-space mobility. Further factors should be assessed in order to achieve more conclusive results about predictors of real-life mobility in communitydwelling older adults.
\end{abstract}

Keywords: Smartphones, Life-space, physical activity

\footnotetext{
* Correspondence: e.giannouli@dshs-koeln.de

${ }^{1}$ Institute of Movement and Sport Gerontology, German Sport University

Cologne, Am Sportpark Müngersdorf 6, 50933 Cologne, Germany

Full list of author information is available at the end of the article
}

(c) The Author(s). 2019 Open Access This article is distributed under the terms of the Creative Commons Attribution 4.0 International License (http://creativecommons.org/licenses/by/4.0/) which permits unrestricted use, distribution, and reproduction in any medium, provided you give appropriate credit to the original author(s) and the source, provide a link to the Creative Commons license, and indicate if changes were made. The Creative Commons Public Domain Dedication waiver (http://creativecommons.org/publicdomain/zero/1.0/) applies to the data made available in this article, unless otherwise stated. 


\section{Background}

Intact mobility is fundamental to healthy aging as it enables older adults to lead active and independent lives. Unfortunately, mobility consistently decreases with advancing age [1, 2], and such reductions have been linked to many adverse consequences for health and functioning. For example, reduced mobility has been linked to low quality of life [3], cognitive decline [4, 5], physical disability [6], falling [7], loss of independence, institutionalization [8], poor health status [9] and ultimately death [10-13].

Given the significance of mobility for independent functioning and the adverse effects of a reduced mobility on health, it is important to have knowledge of factors that have a negative impact on real-life mobility of older adults. Such knowledge may provide input for the further development of interventions aiming to prevent age-related mobility restrictions.

Real-life mobility comprises in-home mobility as part of domestic activities, as well as out-of-home mobility, such as purchasing daily necessities, visiting neighborhood facilities for healthcare or recreation as well as keeping up social relations. Thus, mobility in real-life may include the use of assistive devices (e.g. walking aids) as well as passive means of transportation, such as trains and cars. The above examples illustrate that the extent to which someone is mobile does not only depend on the physical ability to be mobile [14], but that mobility is a complex, multifaceted construct [15] with many potential influencing factors. Literature typically distinguishes two aspects of real-life mobility. One aspect relates to physical activity (i.e. any bodily movement produced by skeletal muscles that requires energy expenditure [16]. This physical activity-based mobility is typically assessed by actigraphy, step counters, or questionnaires. The other aspect is life-space mobility, which refers to the out-of-home/outdoor spatial mobility and includes physical activity-based mobility as well as passive means of transportation, such as trains and cars. Life-space mobility is determined by GPS or questionnaires.

In 2010, Webber et al. [17] introduced a framework including five categories of determinants (cognitive, psychosocial, physical, environmental and financial) which all potentially can influence mobility. Based on a variety of approaches, a number of studies have demonstrated associations of real-life mobility and aspects of physical functioning, such as muscle strength $[18,19]$, cardiovascular fitness [20], gait [21, 22], functional mobility and balance $[14,19,23]$; cognitive factors, such as global cognitive status $[4,24]$, or domain-specific cognitive functions such as working memory $[25,26]$, visuospatial attention $[27,28]$ and executive functioning [26, 29]; psychological factors such as control beliefs [30], outdoor motivation/goals [31, 32], spontaneity [33], depressive symptoms [34], fear of falling [35] and social factors such as social network size [36] and social involvement [37]. Moreover, real-life mobility is associated with socio-demographic factors such as age, gender, income, education [1, 2, 38], as well as environmental conditions such as size of living environment [39] and proximity to relevant destinations [40] or weather conditions [41-43].

These previous studies all investigated aspects of the relationships between real-life mobility and its influencing factors. However, none of the studies presented a comprehensive approach and a number of limitations can be identified: First of all, most of them relied on subjective mobility assessments (i.e. retrospective self-reports/questionnaires) [44] which are susceptible to recall bias due to memory issues and social desirability bias (overreporting good behavior) $[45,46]$ or, as mentioned above, have assessed factors from a single domain of functioning (e.g. only physical or only cognitive), failing to deliver clear-cut conclusions about the extent of contribution that each domain makes to real-life mobility. In addition to this, they have often focused on vulnerable populations with multiple risk factors for mobility restrictions, such as mild cognitive impairment [22, 47] and Parkinson's disease [48] or have looked into single aspects of real-life mobility, e.g. only physical activity [31] or only life-space mobility [49]. However, mobility measures that reflect a person's own activity and mobility measures which reflect life-space mobility may be sometimes related [50] but in essence they are different constructs which consequently may have differential associations with the various domains of functioning. Thus, studies should take this into account and assess all aspects of real-life mobility.

Aiming for a comprehensive approach based on the framework introduced by Webber et al. [17], this study examined associations of potential predictors from multiple domains with real-life mobility in older adults without severe physical and/or cognitive impairments. Our analysis includes different aspects of objectively assessed real-life mobility; measures that reflect a person's physical activity-based mobility as well as measures that reflect lifespace mobility. We hypothesize that physical activitybased mobility will correlate mainly with measures from the physical and psychological domain (rather than the cognitive domain [51]). Life-space mobility, in contrast, (especially measures such as life-space area and maximum action range) captures additional aspects of movement which may include the use of passive means of transportation such as cars, or buses/trams for urban transportation and trains/airplanes for transportation to regions beyond one's city/town of residence, which do not necessarily require high levels of physical capacity, as well as motivational aspects. Since vehicle-related skills such as driving, and use of public transportation require high levels of visuospatial processing (to avoid collisions) [52], executive functioning (to plan routes), and memory (to remember destinations) [25], we hypothesize that life-space mobility 
will correlate mainly with measures from the cognitive and psychosocial domain (e.g. self-efficacy and social network size) rather than the physical domain.

To the best of our knowledge, this is the first study to simultaneously take into account physical, cognitive, psychological, social, environmental and demographical measures in analyzing predictors of real-life mobility, as measured objectively based on physical activity-based mobility as well as life-space mobility, in older adults without severe mobility limitations and/or cognitive impairments.

\section{Methods}

This study was run in two waves; Wave 1: FebruarySeptember 2014 and Wave 2: May-December 2016. All participants underwent an ambulatory mobility assessment over one week (on average) as well as a laboratorybased test battery divided into two sessions. The ambulatory mobility assessment was the same for all participants. The multi-domain, laboratory-based assessment included several physical, cognitive, social and psychometric tests which partly differed between Wave 1 and Wave 2. The local ethics committee approved the study protocol (Wave 1 Registration Nr: 5/2014 and Wave 2 Registration number: 38/2015) which is in accordance with the declaration of Helsinki.

\section{Participants}

Community-dwelling older adults were recruited primarily by handing-out information brochures and holding presentations about the study at local senior citizen gatherings. In total, 157 persons (87 for Wave 1 and 70 for Wave 2) meeting the criteria for participation in the study were initially recruited. Exclusion criteria were: age younger than 60 years, suffering from any serious diseases which could interfere with functional mobility and inability to stand up from a chair independently. All participants signed an informed consent agreeing to participate in the study. Because the test battery of Wave 1 included a stress-test, participants of Wave 1 had to provide a physician's written statement of non-objection for this person to participate.

\section{Real-life Mobility assessment}

Mobility in real life was assessed over one week based on motion (IMU) and positioning (GPS) data from smartphones. The detailed procedure for the ambulatory mobility assessment has been described elsewhere [14]. In short, participants were given a smartphone (Samsung Galaxy $\mathrm{SIII}^{\mathrm{m}}$ ) in an elastic belt which they wore around their waist all day and took off only while sleeping and showering. The real-life data recording took place between the first laboratory session, in which participants received the smartphone, and the second session, in which they returned it. We aimed to record participants' real-life mobility for 7 days.
From the IMU data following two variables were calculated [53]: 'Active- \& Gait Time' (AGT) [h], defined as the sum of active and gait intervals with an intensity higher than 3 METs; and 'Number of steps' (Steps). Since data collection did not target full 24-h periods and registration times differed between days and participants, we adjusted the data by excluding registration periods before 7.00 AM and after 9.00 PM as well as registration periods shorter than $9 \mathrm{~h}$; In order to have consistent assessments for all participants, AGT and Steps scores were then scaled to fit a 12-h day and were subsequently averaged across all registration days of a given participant. Scaled values were calculated as follows: (Actual AGT value for each day * 12) divided by (total registration hours for all activity types).

From the GPS data following three variables were calculated: based on the $\mathrm{R}$ 'chull' function, 'Life-space area' $\left[\mathrm{km}^{2}\right]$ was calculated as the convex hull of all GPS coordinates that were obtained during one day. The available daily life-space area values were then averaged to obtain (average) life-space area per day for each participant; 'total Distance' $[\mathrm{km}]$, defined as the average daily displacement of a person during the registration period; and 'Maximum action range' (AR-max) [km], defined as the largest straight-line distance away from the home location during the registration period. In order to focus on habitual mobility and exclude exceptional trips/extreme values, only data within $15 \mathrm{~km}$ around the participants' home (comparable to the size of the greater area of Cologne, Germany, where the study took place) were included in the analysis [14, 54]. Since GPS reception is usually not possible indoors, the life-space mobility measures primarily cover outdoor mobility. Contrary to the physical activity-based measures, they also cover passive modes of transportation. Figure 1 presents a typical example of GPS data obtained over 7 recording days.

\section{Multi-domain measures}

Three standard demographic measures (age, gender and education) as well as maximum temperature (averaged across all days for each participant's registration period) were used as predictor variables for both study waves. Maximum temperature was included as a weather (environmental) measure since it is known to affect mobility levels $[41,55]$.

In addition to this, three relevant predictors were chosen for each of the four (physical, cognitive, psychological and social) domains of functioning. Each predictor was operationalized by one to four domain-specific measures. Table 1 presents all multi-domain assessments that were administered in Wave 1 and Wave 2.

\section{Statistical analyses}

The variables 'Life-space area', 'total Distance' and 'ARmax' were square-root-transformed to achieve normal 


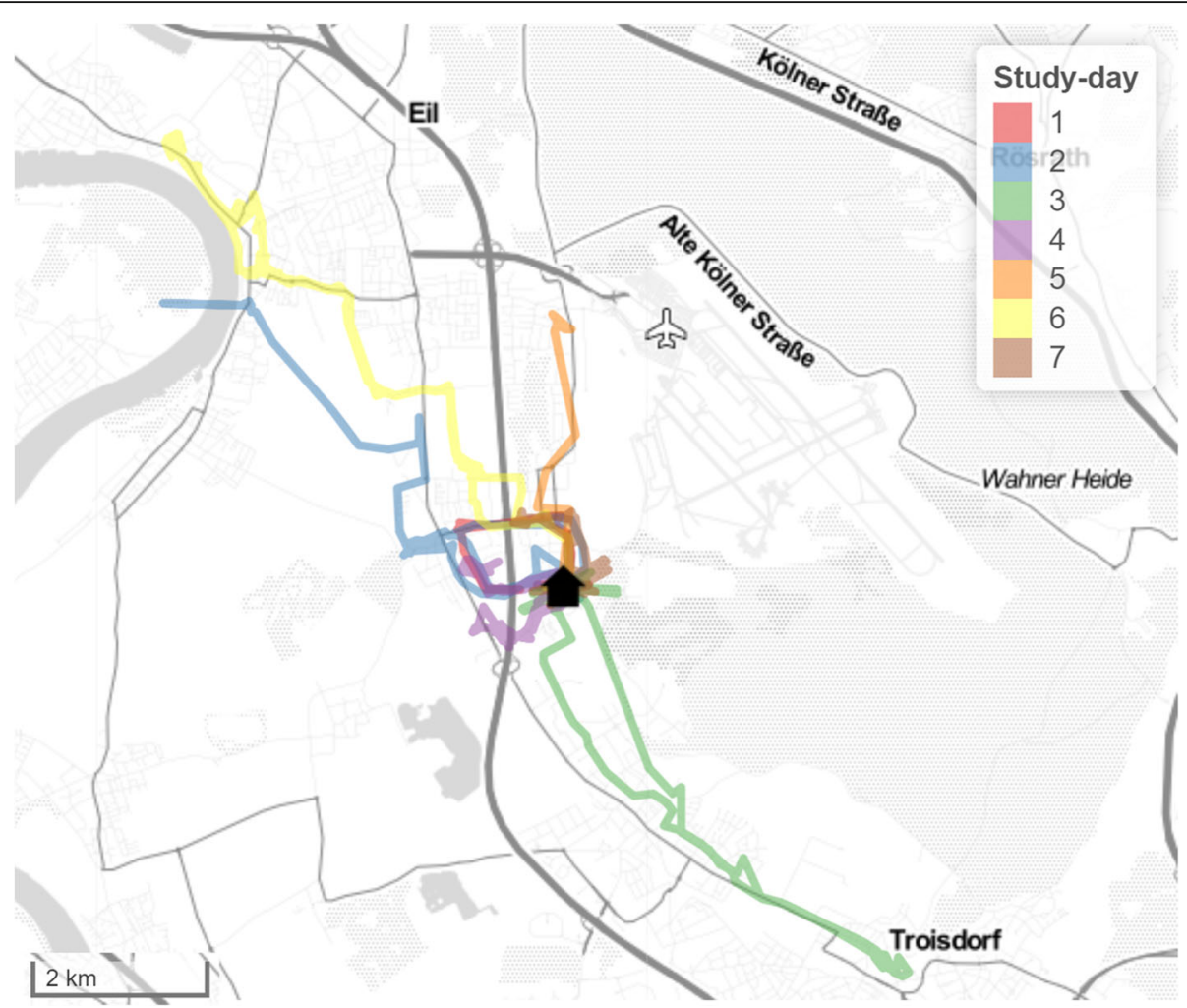

Fig. 1 Sample GPS trajectories of one participant. Note: Each color represents trajectories for different days and the black house symbol represents home location)

distribution. Outlier cases $(0.88 \%)$ were identified using Tukey's outlier filter [73] and removed. Missing data (0$4.3 \%$ for the Wave 1 variables and $0-4.7 \%$ for the Wave 2 variables) were imputed using the pertinent mean values. To make sure that the imputed dataset was not biased, we applied Little's MCAR test, which showed that data were missing randomly. In order to have a first look into the overall relationships between real-life mobility and the various multi-domain measures we performed a multiple correlation analysis (Spearman's rank

Table 1 Laboratory-based assessments for wave 1 and wave 2

\begin{tabular}{|c|c|c|c|c|}
\hline \multirow[b]{2}{*}{ Domains } & \multicolumn{2}{|l|}{ Wave 1} & \multicolumn{2}{|l|}{ Wave 2} \\
\hline & Predictors & Measures (Assessment tools) & Predictors & Measures (Assessment tools) \\
\hline \multirow[t]{3}{*}{ Physical } & Gait & Gait Speed, iTUG [56] & Gait & Gait Speed \\
\hline & Muscle strength & Handgrip Strength, Leg Strength & Muscle strength & Handgrip Strength, Leg Strength \\
\hline & Cardio fitness & PWC 130 & Balance & Jerk, 4SST [57] \\
\hline \multirow[t]{3}{*}{ Cognitive } & Planning ability & HOTAP.A Test [58] & Planning ability & HOTAP.A Test [58] \\
\hline & Visuospatial attention & Attention-Window (AW) test [59] & Visuospatial attention & Attention-Window (AW) Test [59] \\
\hline & Spatial working memory & Grid-Span [60] & Switching & TMT, D2 Test of Attention [61] \\
\hline \multirow[t]{3}{*}{ Psychological } & Self-efficacy & FES [62], GSE [63] & Self-efficacy & FES [64], ABC-D [62], SSE [65], mGES-D [66] \\
\hline & Rigidity & MPTE.2 [67] & Loneliness & UCLA Loneliness Scale (UCLA) [68] \\
\hline & ArousalX & MPTE.1 [67] & Depression & GDS [69] \\
\hline \multirow[t]{3}{*}{ Social } & Sociableness & MPTE.3 [67] & Sociableness & MPTE.3 [67] \\
\hline & Perceived Help Availability & ISEL-TSS [70] & Perceived Help Availability & ISEL-TSS [70] \\
\hline & Perceived Ageism & ASS [71] & Social Networks & LSNS [72] \\
\hline
\end{tabular}

Note: iTUG = instrumented Timed Up-and-Go Test, PWC=Physical Work Capacity Test, HOTAP = Action- and Daily planning, FES=Falls Efficacy Scale, GSE = General SelfEfficacy Scale, MPTE = Multidimensional Personality Test for Adults, ISEL-TSS = Interpersonal Support Evaluation List-Tangible Support Subscale, ASS = Ageism Survey Scale, 4SST = Four Square Step Test, TMT = Trail-Making-Test, ABC-D = German version of the Activities-Specific Balance Confidence, SSE = Stair Self-Efficacy Scale, $m G E S=$ modified Gait Efficacy Scale, GDS = Geriatric Depression Scale, LSNS = Lubben Social Network Scale 
correlation coefficients). Afterwards, a series of stepwise multiple regression analyses were applied, in which the multi-domain factors that were significantly correlated with real-life mobility served as predictors and the reallife mobility measures served as dependent variables. For the stepwise models the limit was $\mathrm{F}=0.10$ for removal and $\mathrm{F}=0.05$ for entry of variables. Normality of the residuals was checked using the Shapiro-Wilk test. For all analyses, the significance level was set at 0.05 ; the only exception was the Kolmogorov-Smirnov test for the normality of datasets, for which the significance level was set at 0.10 .

Correlation as well as the regression analyses were first performed for the two study waves separately and then the common measures were used to complete these analyses with a pooled dataset $(n=154)$ from both studies.

\section{Results}

\section{Descriptive statistics}

From the 157 participants, three were excluded from the analysis: one for dropping out of the study after the first test session and two for not completing the ambulatory mobility assessment. The final sample, therefore, consisted of 85 persons for Wave 1 and 69 persons for Wave 2. As mentioned earlier in the methods section, we aimed for a 7-days mobility assessment. Unfortunately, it was not always possible to organize the sessions exactly 7 days apart. However, only few participants ( $n=9$ for wave 1 , and $n=$ 17 for wave 2 ) had a different number of days $(6,8,9$, or) of mobility registration. In all other participants exactly 7 days were available. Hence, rather than substantially reducing the available complete real-life datasets, and facing the challenge of defining rational criteria for selecting 6 days (out of the 7, 8 or 9), we decided to use total registration times that ranged from 6 to 9 days.

Table 2 provides a description of the samples' demographics as well as real-life mobility measures. Of all reported real-life measures, only 'Total Distance' values were significantly different between wave 1 and wave 2 , therefore, they were excluded from further analysis.

Table 3 summarizes the descriptive data of the multidomain assessments for the two study waves.

\section{Correlation analyses Wave 1}

Table 4 illustrates that all multi-domain assessments except education, maximum temperature, general selfefficacy, MPTE-3 and ISEL-TSS had significant associations with at least one of the real-life measures. Leg strength correlated significantly with all four of the reallife measures but iTUG showed in average the strongest correlations. General self-efficacy (GSS) correlated significantly with only one real-life measure, and Grid-Span
Table 2 Demographic and real-life mobility descriptive data for the two study waves, mean \pm SD or $\%$

\begin{tabular}{lll}
\hline & Wave 1 & Wave2 \\
\hline Age (years) & $72.3 \pm 5.9$ & $69.5 \pm 4.9$ \\
Women & $62 \%$ & $62 \%$ \\
$\quad$ age & $72.4 \pm 5.8$ & $69.0 \pm 4.9$ \\
Men & $38 \%$ & $38 \%$ \\
$\quad$ age & $72.4 \pm 5.9$ & $70.3 \pm 5.0$ \\
BMI (kg/m ${ }^{2}$ ) & $24.3 \pm 3.45$ & $25.3 \pm 4.07$ \\
IPAQ (score) & $7403 \pm 5840$ & $7370 \pm 6539$ \\
Living in assisted living facilities & $15 \%$ & $0 \%$ \\
Gait assistance & $0 \%$ & $0 \%$ \\
Living alone & $50 \%$ & $39 \%$ \\
Higher education degree & $18 \%$ & $26 \%$ \\
Fallers & $19 \%$ & $40 \%$ \\
Reported health problems & $77 \%$ & $93 \%$ \\
Multimorbid & $43 \%$ & $69 \%$ \\
Exercising regularly & $78 \%$ & $77 \%$ \\
Real-life measures & & \\
Mean registration days & $7.6 \pm 1.9$ & $6.7 \pm 1.6$ \\
AGT [h] & $1.07 \pm 0.51$ & $1.13 \pm 0.51$ \\
Steps (n) & $9604 \pm 3539$ & $10,323 \pm 3485$ \\
Life-Space area [km ${ }^{2}$ ] & $11.7 \pm 17.1$ & $13.6 \pm 0.1$ \\
Total Distance $[\mathrm{km}]$ & $23.6 \pm 17.3$ & $40.3 \pm 26.2$ \\
AR-max [km] & $9.44 \pm 4.9$ & $9.70 \pm 4.2$ \\
\hline
\end{tabular}

showed the weakest correlations. Overall, correlation coefficients were low to moderate [74].

\section{Wave 2}

Similar to Wave 1, there were six measures from Wave 2 (maximum temperature, HOTAP.A, Attention Window as well as all the social measures) that did not show significant correlations with real-life measures. The measure which showed the most significant correlations with real-life measures was grip strength, correlating significantly with all four of the real-life measures. However, the strongest correlations were found for the 4SST. The correlation coefficients were low to moderate for this wave as well. Table 5 illustrates all bivariate correlation coefficients between the predictor measures and the real-life measures.

\section{Pooled dataset}

Table 6 summarizes the results of the correlation analysis for the pooled dataset. Grip strength and leg-strength show the largest number and strongest correlations with real-life mobility measures, which hints at the importance of physical measures for real-life mobility overall. 
Table 3 Descriptive data for Wave 1 and Wave 2

\begin{tabular}{|c|c|c|c|c|}
\hline \multirow[b]{2}{*}{ Domain } & \multicolumn{2}{|l|}{ Wave 1} & \multicolumn{2}{|l|}{ Wave 2} \\
\hline & Measures & Mean $( \pm S D)$ & Mean $( \pm S D)$ & Measures \\
\hline \multirow[t]{5}{*}{ Physical } & Grip Strength [N] & $281.65( \pm 111.72)$ & $283.84( \pm 114.85)$ & Grip Strength [N] \\
\hline & Leg Strength $\left[\mathrm{Kg}_{N E} / \mathrm{Kg}_{B W}\right]$ & $1.43( \pm 0.45)$ & $1.48( \pm 0.46)$ & Leg Strength $\left[K g_{N E} / K g_{B W}\right]$ \\
\hline & PWC & $1.61( \pm 0.88)$ & $0.0858( \pm 0.059)$ & Jerk $\left[\mathrm{m} / \mathrm{s}^{3}\right]$ \\
\hline & iTUG [s] & $16.01( \pm 2.61)$ & $7.73( \pm 1.66)$ & 4SST \\
\hline & Gait speed $[\mathrm{m} / \mathrm{s}]$ & $1.35( \pm 0.16)$ & $1.42( \pm 0.14)$ & Gait speed $[\mathrm{m} / \mathrm{s}]$ \\
\hline \multirow[t]{4}{*}{ Cognitive } & HOTAP.A & $10.3( \pm 4.59)$ & $13.3( \pm 4.33)$ & HOTAP.A \\
\hline & Attention Window & $69.3( \pm 22.54)$ & $32.1( \pm 11.16)$ & Attention Window \\
\hline & Grid-Span & $3.85( \pm 0.93)$ & $144.5( \pm 44.01)$ & $\mathrm{d} 2$ \\
\hline & & & $50.14( \pm 24.57)$ & TMT (B-A) \\
\hline \multirow[t]{6}{*}{ Psychological } & FES & $19.34( \pm 4.04)$ & $19.35( \pm 4.39)$ & FES \\
\hline & GSE & $33.05( \pm 4.93)$ & $83.48( \pm 22.32)$ & SSE \\
\hline & MPTE.1 & $8.02( \pm 2.06)$ & $90.56( \pm 12.91)$ & $A B C$ \\
\hline & MPTE.2 & $9.41( \pm 2.34)$ & $89.2( \pm 15.74)$ & mGES-D \\
\hline & & & $54.07( \pm 4.26)$ & UCLA \\
\hline & & & $1.39( \pm 1.68)$ & GDS \\
\hline \multirow[t]{3}{*}{ Social } & MPTE.3 & $2.56( \pm 2.2)$ & $2.44( \pm 1.91)$ & MPTE.3 \\
\hline & ISEL-TSS & $20.24( \pm 3.81)$ & $21.13( \pm 3.4)$ & ISEL-TSS \\
\hline & ASS & $4.79( \pm 6.73)$ & $33.1( \pm 7.4)$ & LSNS \\
\hline
\end{tabular}

Note: $K g_{N E} / K g_{B W}=$ Knee extensor strength $(\mathrm{kg})$ normalized for body weight $(\mathrm{kg}), B-A=$ points for part $B$ of the Trail-Making Test minus points for part $A$ of the TrailMaking Test, iTUG = instrumented Timed Up-and-Go Test, PWC=Physical Work Capacity Test, HOTAP=Action- and Daily planning, FES=Falls Efficacy Scale, GSE = General Self-Efficacy Scale, MPTE = Multidimensional Personality Test for Adults, ISEL-TSS = Interpersonal Support Evaluation List-Tangible Support Subscale, ASS = Ageism Survey Scale, 4SST = Four Square Step Test, TMT = Trail-Making-Test, ABC-D = German version of the Activities-Specific Balance Confidence, SSE =Stair Self-Efficacy Scale, $m G E S=$ modified Gait Efficacy Scale, GDS = Geriatric Depression Scale, LSNS = Lubben Social Network Scale

\section{Regression analyses}

To evaluate the predictive ability of the domain specific measures for each of the real-life measures four stepwise multiple regression analyses were conducted for each dataset (Wave 1, Wave 2 and pooled dataset). The predictor variables were checked for multicollinearity, and all variance inflation factor values were below 1.117 indicating no multicollinearity among factors. Their results are summarized in Table 7.

The best predictive model (i.e. the model with the highest adjusted coefficient of determination) for all three datasets was AGT ( $\mathrm{R}^{2}$ between 14 and $30 \%$ ), which had three significant predictors for Wave 2 and two significant predictors for Wave 1 and the pooled dataset, respectively. Most of the regression models had one or two significant predictors. 'AGT' of Wave 2 had three predictors. The predictor measures explained a somewhat larger proportion of variance in real-life measures for Wave 1 (between 6 and 28\%) and Wave 2 (between 8 and 30\%) compared to the pooled dataset (between 5 and 14\%).

Strength measures (and especially leg strength) were retained in all but four of the regression models across all datasets. Adding iTUG, which was retained in another one model, it is clear that measures from the physical domain were the most important for real-life measures.
Demographic variables also seem to be important for reallife mobility, especially age, which was retained in four regression models followed by education, which was retained in two physical activity-based models (AGT and Steps). Neither cognitive nor social measures were retained in any of the models. Psychological measures (rigidity and self-efficacy measures) were retained in five regression models from Wave 1 and Wave 2. Overall, the analyses indicated that the predictors accounted for a significant but low proportion of variance (between 5 and $30 \%)$ in real-life measures.

\section{Discussion}

In the current work we aimed to examine the predictive value of demographic and environmental factors, as well as factors from four domains of functioning (physical, cognitive, psychological, social), for real-life mobility of community-dwelling older adults. Our data provide support for our first hypothesis that physical activity-based mobility is associated with physical and psychological functioning, but do not support our second hypothesis that life-space mobility is more associated with sociocognitive functioning.

Physical measures, and especially strength, showed the highest associations with real-life mobility (both for 
Table 4 Correlation coefficients $r_{s}$ between all real-life mobility measures and multi-domain measures for Wave 1. ( $* p<.05$;

\begin{tabular}{|c|c|c|c|c|c|}
\hline Domain & & AGT & Steps & Life-Space area & AR-max \\
\hline & Age & $-.332^{* *}$ & -.124 & $-.256^{* *}$ & $-.256^{* *}$ \\
\hline & Gender & .148 & .146 & $.189^{*}$ & .097 \\
\hline & Education & -.059 & -.093 & .113 & .038 \\
\hline & Maximum Temperature & -.097 & -.133 & -.169 & -.129 \\
\hline \multirow[t]{5}{*}{ Physical } & Grip Strength & $.251^{*}$ & .121 & $.329^{* *}$ & $.184^{*}$ \\
\hline & Leg Strength & $.336^{* *}$ & $.274^{* *}$ & $.286^{* *}$ & $.263^{* *}$ \\
\hline & Physical Work Capacity Test & .17 & $.258^{* *}$ & -.079 & .021 \\
\hline & iTUG & $-.429^{* *}$ & $-.237^{*}$ & -.161 & -.087 \\
\hline & Gait Speed & $.346^{* *}$ & $.201^{*}$ & .146 & .067 \\
\hline \multirow[t]{3}{*}{ Cognitive } & HOTAP.A & $.266^{* *}$ & .028 & $.250^{*}$ & $.257^{* *}$ \\
\hline & Attention Window & $.332^{* *}$ & .137 & $.249^{*}$ & $.209^{*}$ \\
\hline & Grid-Span & $.194^{*}$ & .128 & $.204^{*}$ & $.180^{*}$ \\
\hline \multirow[t]{4}{*}{ Psychological } & Falls Efficacy Scale & $-.229^{*}$ & -.126 & -.093 & $-.191^{*}$ \\
\hline & General Self-Efficacy & -.101 & -.137 & -.094 & -.096 \\
\hline & MPTE.1 (arousal) & $-.301^{* *}$ & $-.267^{* *}$ & -.029 & -.162 \\
\hline & MPTE.2 (rigidity) & $-.390^{* *}$ & $-.382^{* *}$ & -.055 & -.109 \\
\hline \multirow[t]{3}{*}{ Social } & MPTE.3 (sociableness) & -.035 & .002 & .127 & .073 \\
\hline & ISEL-TSS & .132 & .032 & .145 & .146 \\
\hline & Ageism Survey Scale & $-.246^{*}$ & $-.261^{* *}$ & -.119 & $-.186^{*}$ \\
\hline
\end{tabular}

Note: iTUG = instrumented Timed Up-and-Go test, HOTAP = Action- and Daily planning,, MPTE = Multidimensional Personality Test for Adults, ISEL-TSS = Interpersonal Support Evaluation List-Tangible support subscale

physical activity-based mobility as well life-space mobility). This is in line with previous epidemiological studies that have reported associations between physical activity [18], or life-space mobility [33], with several aspects of physical functioning. Since our GPS analysis didn't differentiate between active and passive modes of transportation, it may be that our participants made little use of passive transportation and instead were mainly physically active, which would explain the clear associations of physical and not so much of cognitive and psychosocial measures with lifespace mobility.

Contrary to our expectations, cognitive and social functioning showed no associations with real-life mobility. Although a plethora of cross-sectional $[27,36,75]$ as well as longitudinal studies [76] show significant associations, discrepant results have also been reported [77, 78]. Regarding cognition, models with cognitive measures as a sole predictor are usually significant; however, adding other predictors often renders cognition non-significant [34]. It is possible that the role of cognition for real-life mobility, and especially life-space mobility, would be different/more important, if participants with cognitive impairments were included in the study. Also, some of the strongest and most usual intervening variables modifying the relationship between mobility and cognition are psychological measures; studies have reported on the interplay and mediating role of several psychological measures such as depression [34] or motivational resources [29] for the association between mobility and cognition, however again with mixed results. The importance of psychological measures especially that of rigidity (MPTE.2) and self-efficacy for mobility in old age is also evident in our results, though much more pronounced for physical activity-based mobility than lifespace mobility. MPTE.2 remained as a significant predictor in the models of AGT and steps. This is in line with Tung et al. [22] as well as Tanaka \& Yamagami [33], who reported significant association between lifespace and apathy as well as spontaneity, both constructs very similar to rigidity. Furthermore, the importance of self-efficacy for real-life mobility is depicted in the results of Wave 2, which are in accordance with Amireault et al. [31] and Bauman et al. [79], as well as Auais et al. [35], highlighting the role of self-efficacy for physical activity as well as life-space. Interestingly, compared with Wave 1, self-efficacy measures were much more associated with mobility in Wave 2 . This can be explained by the fact that for Wave 2 self-efficacy was assessed much more comprehensively, both in terms of number of measures (two measures used in wave 1 and four measures used in wave 2) as well as in terms of their specificity (wave 1 included a general self-efficacy scale, whereas 
Table 5 Correlation coefficients $r_{s}$ between all real-life mobility measures and multi-domain measures for Wave 2. ( $* p<.05$; $* * p<.01)$

\begin{tabular}{|c|c|c|c|c|c|}
\hline Domain & & AGT & Steps & Life-Space area & AR-max \\
\hline & Age & $-.397^{* *}$ & -.177 & -.043 & -.101 \\
\hline & Gender & -.09 & -.036 & $.340^{* *}$ & $.349^{* *}$ \\
\hline & Education & $.372^{* *}$ & $.285^{* *}$ & .031 & .12 \\
\hline & Maximum Temperature & -.007 & -.019 & -.099 & -.077 \\
\hline \multirow[t]{5}{*}{ Physical } & Grip Strength & $.319^{* *}$ & $.283^{* *}$ & $.201^{*}$ & $.205^{*}$ \\
\hline & Leg Strength & .065 & -.007 & $.240^{*}$ & $.239^{*}$ \\
\hline & Jerk & $-.314^{* *}$ & -.184 & -.072 & -.035 \\
\hline & Four Square Step Test & $-.431^{* *}$ & $-.218^{*}$ & -.038 & .011 \\
\hline & Gait Speed & $.218^{*}$ & .197 & .028 & .056 \\
\hline \multirow[t]{4}{*}{ Cognitive } & HOTAP.A & .198 & .037 & .05 & .068 \\
\hline & Trail Making Test (B-A) & $-.306^{* *}$ & -.177 & -.02 & -.05 \\
\hline & $\mathrm{d} 2$ Test of Attention & $.201^{*}$ & .082 & .155 & .148 \\
\hline & Attention Window & -.006 & -.07 & .002 & .084 \\
\hline \multirow[t]{6}{*}{ Psychological } & Falls Efficacy Scale & $-.206^{*}$ & -.19 & .072 & $.410^{*}$ \\
\hline & Stair Self-Efficacy Scale & $.277^{*}$ & $.217^{*}$ & -.001 & .006 \\
\hline & $A B C-D$ & $.265^{*}$ & $.212^{*}$ & .001 & -.005 \\
\hline & mGES-D & $.229^{*}$ & $.211^{*}$ & -.018 & .077 \\
\hline & UCLA loneliness scale & -.074 & -.117 & -.037 & -.025 \\
\hline & Geriatric Depression Scale & $-.234^{*}$ & $-.267^{*}$ & .101 & .02 \\
\hline \multirow[t]{3}{*}{ Social } & Lubben Social Network Scale & .005 & -.111 & .047 & .149 \\
\hline & MPTE3 & -.132 & -.176 & .061 & -.027 \\
\hline & ISEL-TSS & .001 & .054 & .073 & .136 \\
\hline
\end{tabular}

Note: $A B C-D=$ German version of the Activities-Specific Balance Confidence, $m G E S=$ modified Gait Efficacy Scale, MPTE = Multidimensional Personality Test for Adults, LSNS = Lubben Social Network Scale

Table 6 Correlation coefficients $r_{s}$ between all real-life mobility measures and multi-domain measures for the pooled dataset. $(* p<.05 ; * * p<.01)$

\begin{tabular}{llllll}
\hline Domain & & AGT & Steps & Life-Space area & $-.194^{* *}$ \\
\hline & Age & $-.366^{* *}$ & $-.166^{*}$ & $-.191^{* *}$ & $.233^{* *}$ \\
& Gender & .033 & .064 & .072 & .003 \\
& Education & $.173^{* *}$ & .13 & -.102 & -.102 \\
& Max. Temperature & -.05 & -.08 & $.251^{* *}$ & $.191^{* *}$ \\
Physical & Grip Strength & $.276^{* *}$ & $.181^{*}$ & $.221^{* *}$ & $.250^{* *}$ \\
& Leg Strength & $.265^{* *}$ & $.216^{* *}$ & .108 & .117 \\
Cognitive & Gait speed & $.233^{* *}$ & $.138^{*}$ & $.216^{* *}$ & $.176^{*}$ \\
& HOTAP.A & $.221^{* *}$ & .051 & -.021 & -.088 \\
Psychological & Attention Window & .023 & -.052 & -.01 & .048 \\
Social & Falls Efficacy Scale & $-.217^{* *}$ & $-.147^{*}$ & .035 \\
& MPTE3 & -.076 & -.077 & .052 & .132 \\
\hline
\end{tabular}


Table 7 Predictors with their standardized regression coefficients and the adjusted coefficients of determination for the physical activity-based and the life-space models of Wave 1, Wave 2 and the pooled dataset $(* p<.05 ; * * p<.01)$

\begin{tabular}{|c|c|c|c|c|c|c|c|}
\hline \multicolumn{4}{|c|}{ Physical activity-based mobility } & \multicolumn{4}{|c|}{ Life-space mobility } \\
\hline \multicolumn{2}{|l|}{$\overline{A G T}$} & \multicolumn{2}{|l|}{ Steps } & \multicolumn{2}{|l|}{ Life-Space area } & \multicolumn{2}{|l|}{ AR-max } \\
\hline Predictors & Beta & Predictors & Beta & Predictors & Beta & Predictors & Beta \\
\hline \multicolumn{8}{|c|}{ Wave 1} \\
\hline iTUG. & $-.362^{*}$ & MPTE.2 & $-.371^{* *}$ & Leg Strength & $.271^{*}$ & Leg Strength & $.266^{*}$ \\
\hline \multirow[t]{2}{*}{ MPTE.2 } & $-.325^{* *}$ & Leg Strength & $.221^{*}$ & & & Age & $-.341^{*}$ \\
\hline & $\mathrm{R}^{2}=.280^{* *}$ & & $\mathrm{R}^{2}=.183^{* *}$ & & $\mathrm{R}^{2}=.063^{*}$ & & $\mathrm{R}^{2}=.142^{*}$ \\
\hline \multicolumn{8}{|c|}{ Wave 2} \\
\hline Age & $-.294^{*}$ & mGES-D & $.310^{*}$ & Grip Strength & $.341^{*}$ & FES & $-.299^{*}$ \\
\hline Education & $.325^{* *}$ & Education & $.235^{*}$ & & & & \\
\hline \multirow[t]{2}{*}{ SSE } & $.277^{*}$ & & & & & & \\
\hline & $\mathrm{R}^{2}=.303^{* *}$ & & $\mathrm{R}^{=2}=.136^{*}$ & & $\mathrm{R}^{2}=.103^{*}$ & & $\mathrm{R}^{2}=.076^{*}$ \\
\hline \multicolumn{8}{|c|}{ Pooled dataset } \\
\hline Age & $-.287^{* *}$ & Leg Strength & $.232^{*}$ & Grip Strength & $.297^{* *}$ & Grip Strength & $.244^{*}$ \\
\hline \multirow[t]{2}{*}{ Leg Strength } & $.201^{*}$ & & & & & Age & $-.198^{*}$ \\
\hline & $\mathrm{R}^{2}=.142^{* *}$ & & $\mathrm{R}^{2}=.048^{*}$ & & $\mathrm{R}^{2}=.082^{* *}$ & & $\mathrm{R}^{2}=.113^{* *}$ \\
\hline
\end{tabular}

wave 2 included only mobility-related self-efficacy measures). According to Bandura [80] there is no allpurpose measure of perceived self-efficacy; assessments should be tailored to the specific domain of functioning that is the object of interest. Indeed, mGES-D, a tool assessing self-efficacy specifically for walking, remained as a significant predictor for the 'Steps' model, whereas SSE, a tool assessing self-efficacy for stair climbing remained as a predictor for AGT, which covers a wider spectrum of activities than just walking, including stairclimbing.

While previous studies report strong associations between environmental (e.g. weather) factors [41] with real-life mobility, our results are in line with Ullrich et al. (2019) [47] who did not find any associations between life-space mobility and several weather parameters. In our dataset maximum temperature did not show any correlations with any of the real-life measures although this specific weather measure has shown to be one of the best predictors of physical activity in older people [55] and although there was enough variation in maximum temperature on the days of data collection periods $\left(\right.$ Min $=10.6{ }^{\circ} \mathrm{C}, \operatorname{Max}=29.5^{\circ} \mathrm{C}$, Mean $=21.5^{\circ} \mathrm{C}, \mathrm{SD}=$ $3.7^{\circ} \mathrm{C}$ ). Therefore, the role of additional weather measures for real-life mobility, such as precipitation and sunshine hours, should be assessed further.

Finally, two of the three of the assessed demographic measures showed associations with real-life measures; gender did not seem to affect real-life mobility. Age was associated with both physical activity-based as well as life-space measures, whereas education only with physical activity measures. The latter can be explained by the fact that highly educated individuals are more likely to remain physically active due to their awareness of the positive effects of an active lifestyle for health and quality of life.

Although the current study has the strength of examining the relationship between objectively measured physical activity-based and life-space measures with a wide range of potential multi-domain mobilityinfluencing factors, there are still other important factors that potentially have a large influence on real-life mobility, such as (perceived) walkability of the neighborhood, proximity and accessibility of points of interest, neighborhood satisfaction [81] and personality traits [37], which were not assessed in this study. This possibly explains the rather low proportion of variance that our predictors explained for real-life mobility overall, and especially for life-space mobility measures. However, despite a lower proportion of explained variance, our results are similar to the only study that has used Webber's comprehensive framework [17] to look into multidomain determinants for life-space mobility in older adults with cognitive impairments [47] which found that physical and psychosocial measures (and not cognitive, financial, environmental, cultural and biographical measures) accounted for $36 \%$ in life-space mobility. Further limitations include the cross-sectional design of this study, which does not allow causal conclusions, the sample size and type, which was limited to rather high-functioning and active older adults, prohibiting the generalization of this study's results to other populations as well as the two different samples with somewhat large differences in some of the common functioning measures (e.g. 
Attention Window) as well as background measures which might have affected the results of the pooled data analyses. Finally, the correlation values have not been corrected for multiple testing, thus, there might be false positives in the variable selection for the regression analyses.

Future studies should examine other types of samples, e.g. frail or inactive individuals and apply longitudinal designs looking into the change of real-life mobility and the remainder of potential influencing factors over time, preferably also factors that have not been assessed in this study such as (perceived) walkability of the neighborhood, proximity and accessibility of points of interest, and overall neighborhood satisfaction, as well as several skills like driving, access to a vehicle etc.

\section{Conclusions}

Given its limitations and its exploratory character, this study cannot provide a definitive answer regarding the factors that predict physical activity and life-space mobility. However, it provides first important insights on the relative contribution of multi-domain factors for real-life mobility. Primarily physical, but also psychological factors, were stronger predictors of real-life mobility (than cognitive and social). Therefore, they may be targets for interventions aiming to improve real-life mobility in community-dwelling older adults without severe mobility limitations. Specifically, such interventions could combine physical exercise with strengthening of self-efficacy, e.g., through social networks, motivation strategies or approaches based on Social Cognitive Theory [82]. However, there is still a large proportion of variance that remains unexplained, especially for lifespace mobility, which indicates that there are other factors that play a role for real-life mobility in older adults which have not been assessed in this study which might also have implications for interventions that do not address functioning but rather unmodifiable/hard to modify factors such as urban planning.

\section{Acknowledgments}

We would like to gratefully acknowledge the assistance of Rieke Trumpf, Lisa Kosler and Tobias Haase in data collection and the assistance of Bärbel Barth in the recruitment of participants from the assisted-living facilities as well as all study's participants.

\section{Authors' contributions}

$E G, O B$ and WZ conceptualized the study. EG and OB designed the project. EG collected the data. MF and RW processed the GPS data. SM processed the inertial sensor data. EG analyzed the data and was the major contributor in writing this manuscript. All authors read and approved the final manuscript.

\section{Funding}

This study was funded by a grant from the German Sport University to the Graduate College 'Reduced Mobility in Old Age' and by the European Commission (FARSEEING, Seventh Frame- work Program, Cooperation-ICT, Grant Agreement No. 288940). The funders were not involved in the design of the study or in collection, analysis, and interpretation of data.

\section{Availability of data and materials}

The datasets used and/or analyzed during the current study are available from the corresponding author on reasonable request.

Ethics approval and consent to participate

All participants provided written informed consent and the Ethics Committee of the German Sport University Cologne had approved the study (Wave 1 Registration Nr: 5/2014 and Wave 2 Registration number: 38/2015).

\section{Consent for publication \\ Not applicable.}

\section{Competing interests}

The authors declare that they have no competing interests.

\section{Author details}

'Institute of Movement and Sport Gerontology, German Sport University Cologne, Am Sportpark Müngersdorf 6, 50933 Cologne, Germany. ${ }^{2}$ University Research Priority Program 'Dynamics of Healthy Aging', University of Zurich, Andreasstrasse 15, 8050 Zurich, Switzerland. ${ }^{3}$ Department of Geography, University of Zurich, Winterthurerstrasse 190, 8057 Zurich, Switzerland. ${ }^{4}$ Department of Electrical, Electronic, and Information Engineering, University of Bologna, Viale Risorgimento 2, 40136 Bologna, Italy. Institute of Physiology and Anatomy, German Sport University Cologne, Am Sportpark Müngersdorf 6, 50933 Cologne, Germany.

Received: 17 April 2019 Accepted: 9 October 2019

Published online: 03 November 2019

\section{References}

1. Hallal PC, Andersen LB, Bull FC, Guthold R, Haskell W, Ekelund U, et al. Global physical activity levels: surveillance progress, pitfalls, and prospects. Lancet (London, England) [Internet]. 2012 [cited 2018 Nov 12];380(9838): 247-57. Available from: http://www.ncbi.n/m.nih.gov/pubmed/22818937.

2. Peel C, Sawyer Baker P, Roth DL, Brown CJ, Brodner EV, Allman RM. Assessing mobility in older adults: the UAB Study of aging life-space assessment. Phys Ther. 2005;85:1008-119.

3. Rantakokko M, Portegijs E, Viljanen A, Iwarsson S, Kauppinen M, Rantanen T. Changes in life-space mobility and quality of life among communitydwelling older people: a 2-year follow-up study. Qual Life Res [Internet]. 2016 Sep 25 [cited 2016 Mar 13]; Available from: http://www.ncbi.nlm.nih. gov/pubmed/26407605.

4. Crowe M, Andel R, Wadley VG, Okonkwo OC, Allman RM. Life-Space and Cognitive Decline in a Community-Based Sample of African American and Caucasian Older Adults. J Gerontol. 2010;63(11).

5. Buchman AS, Boyle PA, Yu L, Shah RC, Wilson RS, Bennett DA. Total daily physical activity and the risk of $A D$ and cognitive decline in older adults. Neurology [Internet]. 2012 Apr 24 [cited 2015 Oct 28];78(17):1323-9. Available from: http://www.neurology.org/content/78/17/1323.abstract

6. Hirvensalo M, Rantanen T, Heikkinen E. Mobility difficulties and physical activity as predictors of mortality and loss of independence in the community-living older population. J Am Geriatr Soc [Internet]. 2000 May 1 [cited 2015 May 31];48(5):493-8. Available from: http://europepmc.org/ abstract/med/10811541

7. Rubenstein LZ, Powers CM, MacLean CH. Quality Indicators for the Management and Prevention of Falls and Mobility Problems in Vulnerable Elders. Ann Intern Med [Internet]. 2001 Oct 16 [cited 2015 May 31];135(8_ Part_2):686. Available from: http://annals.org/article.aspx?articleid=714861

8. von Bonsdorff M, Rantanen T, Laukkanen P, Suutama T, Heikkinen E. Mobility limitations and cognitive deficits as predictors of institutionalization among community-dwelling older people. Gerontology [Internet]. 2006 Jan 10 [cited 2015 May 10];52(6):359-65. Available from: https://jyx.jyu.fi/dspace/ handle/123456789/38174

9. Kennedy RE, Williams CP, Sawyer P, Lo AX, Connelly K, Nassel A, et al. LifeSpace Predicts Health Care Utilization in Community-Dwelling Older Adults. J Aging Health [Internet]. 2019 Feb 14 [cited 2019 Jan 15];31(2):280-92. Available from: http://journals.sagepub.com/doi/10.1177/0898264317730487

10. Mackey DC, Lui L-Y, Cawthon PM, Ensrud K, Yaffe K, Cummings SR. LifeSpace Mobility and Mortality in Older Women: Prospective Results from the Study of Osteoporotic Fractures. J Am Geriatr Soc [Internet]. 2016 Oct [cited 
2016 Nov 16];64(11):2226-34. Available from: http://doi.wiley.com/10.1111/ jgs. 14474

11. Klenk J, Dallmeier D, Denkinger MD, Rapp K, Koenig W, Rothenbacher D, et al. Objectively Measured Walking Duration and Sedentary Behaviour and FourYear Mortality in Older People. PlosOne [internet]. 2016; Available from: http:// journals.plos.org/plosone/article/asset?id=10.1371/journal.pone.0153779.PDF

12. Stenholm S, Koster A, Valkeinen H, Patel KV, Bandinelli S, Guralnik JM, et al. Association of Physical Activity History with Physical Function and Mortality in old age. J Gerontol a biol Sci med Sci [Internet]. 2015;71(4):496-501. Available from. http://www.ncbi.nIm.nih.gov/pubmed/26290538.

13. Schmid D, Ricci C, Leitzmann MF. Associations of objectively assessed physical activity and sedentary time with all-cause mortality in US adults: the NHANES study. PLoS One [Internet]. 2015 Jan [cited 2016 Mar 22];10(3): e0119591. Available from: http://journals.plos.org/plosone/article?id=10.13 71/journal.pone.0119591

14. Giannouli E, Bock O, Mellone S, Zijlstra W. Mobility in old age: capacity is not performance. Biomed Res Int. 2016;2016.

15. Thompson D, Peacock O, Western M, Batterham AM. Multidimensional physical activity: an opportunity, not a problem. Exerc Sport Sci Rev [Internet]. 2015 [cited 2017 Jan 19];43(2):67-74. Available from: http://www. ncbi.nlm.nih.gov/pubmed/25607280.

16. Caspersen CJ, Powell KE, Christenson GM. Physical activity, exercise, and physical fitness: definitions and distinctions for health-related research. Public Health Rep [Internet]. 1985 [cited 2019 Jul 25];100(2):126-31. Available from: http://www.ncbi.nlm.nih.gov/pubmed/3920711.

17. Webber S, Porter MM, Menec VH. Mobility in older adults: a comprehensive framework. Gerontologist [Internet]. 2010 [cited 2014 may 15];50(4):443-50. Available from: http://www.ncbi.nlm.nih.gov/pubmed/20145017.

18. Morie M, Reid KF, Miciek R, Lajevardi N, Choong K, Krasnoff JB, et al. Habitual physical activity levels are associated with performance in measures of physical function and mobility in older men. J Am Geriatr Soc [Internet]. 2010 Sep [cited 2015 Jul 19];58(9):1727-33. Available from: http:// www.pubmedcentral.nih.gov/articlerender.fcgi?artid $=2945416 \&$ tool $=$ pmcentrez\&rendertype $=$ abstract

19. Rapp K, Klenk J, Benzinger P, Franke S, Denkinger MD, Peter R. Physical performance and daily walking duration: associations in 1271 women and men aged 65-90 years. Aging Clin Exp Res [Internet]. 2012 [cited $2015 \mathrm{Jul}$ 19];24(5):455-60. Available from: http://www.ncbi.nlm.nih.gov/ pubmed/22313581.

20. Harada K, Lee S, Lee S, Bae S, Harada K, Suzuki T, et al. Objectively-measured outdoor time and physical and psychological function among older adults. Geriatr Gerontol Int [Internet]. 2016 [cited 2016 Dec 8]; Available from: http://doi.wiley.com/10.1111/ggi.12895

21. Rojer AGM, Reijnierse EM, Trappenburg MC, van Lummel RC, Niessen M, van Schooten KS, et al. Instrumented Assessment of Physical Activity Is Associated With Muscle Function but Not With Muscle Mass in a General Population. J Aging Health [Internet]. 2017 Jul 24 [cited 2017 Oct 14]; 089826431772155. Available from: http://journals.sagepub.com/doi/10.1177/ 0898264317721554

22. Tung JY, Rose RV, Gammada E, Lam I, Roy EA, Black SE, et al. Measuring life space in older adults with mild-to-moderate Alzheimer's disease using mobile phone GPS. Gerontology [Internet]. 2014 Jan 1 [cited 2015 Apr 22]; 60(2):154-62. Available from: http://europepmc.org/abstract/med/24356464

23. Blamoutier M, Boissy P, Brière S, Faucher G, Lauzé M, Duval C. Is a decrease of grip strength associated with community mobility restriction in dynapenic older women? JCSM Clin Reports [Internet]. 2018 May 30 [cited 2018 Jun 4];3(1). Available from: https://jcsm-clinical-reports.info/index.php/ jcsm-cr/article/view/42

24. Blondell SJ, Hammersley-Mather R, Veerman J, Mortazavi S, Mohammad K, Ardebili $\mathrm{H}$, et al. Does physical activity prevent cognitive decline and dementia?: A systematic review and meta-analysis of longitudinal studies. BMC Public Health [Internet]. 2014 [cited 2016 Jul 5];14(1):510. Available from: http:// bmcpublichealth.biomedcentral.com/articles/10.1186/1471-2458-14-510

25. Wettstein M, Wahl H, Diehl MK. A multidimensional view of out-of-home behaviors in cognitively unimpaired older adults : examining differential effects of related predictors. Eur J Ageing. 2014:1-13.

26. Zhu W, Howard VJ, Wadley VG, Hutto B, Blair SN, Vena JE, et al. Association Between Objectively Measured Physical Activity and Cognitive Function in Older Adults-The Reasons for Geographic and Racial Differences in Stroke Study. J Am Geriatr Soc [Internet]. 2015 [cited 2016 Jan 18];63(12):2447-54. Available from: http://www.ncbi.nlm.nih.gov/pubmed/26691697.
27. Giannouli E, Bock O, Zijlstra W. Cognitive functioning is more closely related to real-life mobility than to laboratory-based mobility parameters. Eur J Ageing [Internet]. 2017 Jun 20 [cited 2017 Jun 20];1-9. Available from: http://link.springer.com/10.1007/s10433-017-0434-3

28. Loprinzi PD, Edwards MK, Crush E, lkuta T, Del Arco A. Dose-Response Association Between Physical Activity and Cognitive Function in a National Sample of Older Adults. Am J Heal Promot [Internet]. 2017 [cited 2017 Feb 1];089011711668973. Available from: http://journals.sagepub.com/doi/10.11 77/0890117116689732

29. Wahl H, Wettstein M, Shoval N, Oswald F, Kaspar R, Issacson M, et al. Interplay of Cognitive and motivational resources for out-of-home behavior in a sample of cognitively heterogeneous Older Adults : findings of the SenTra project. Journals Gerontol Ser B Psychol Sci Soc Sci. 2013:68(5):691-702.

30. Sartori AC, Wadley VG, Clay OJ, Parisi JM, Crowe M. The relationship between cognitive function and life-space: The potential role of personal control beliefs. Psychol Aging. 2012;27(2):364-74.

31. Amireault S, Godin G, Vézina-Im L-A. Determinants of physical activity maintenance: a systematic review and meta-analyses. Health Psychol Rev [Internet]. 2013 Mar [cited 2016 Nov 22];7(1):55-91. Available from: http:// www.tandfonline.com/doi/abs/10.1080/17437199.2012.701060

32. Saajanaho $M$, Rantakokko M, Portegijs E, Törmäkangas T, Eronen J, Tsai L-T, et al. Personal goals and changes in life-space mobility among older people. Prev Med (Baltim) [Internet]. 20151 [cited 2018 Nov 4];81:163-7. Available from: https://www.sciencedirect.com/science/article/pii/S0091 743515002674

33. Tanaka S, Yamagami T. Life-space and related factors for the elderly in a geriatric Health service facility. Prog Rehabil Med. 2018;3:1-9.

34. Béland F, Julien D, Bier N, Desrosiers J, Kergoat M-J, Demers L. Association between cognitive function and life-space mobility in older adults: results from the FRéLE longitudinal study. BMC Geriatr [lnternet]. 2018 [cited 2018 Sep 30];18(1):227. Available from: https://bmcgeriatr.biomedcentral.com/ articles/10.1186/s12877-018-0908-y

35. Auais M, Alvarado B, Guerra R, Curcio C, Freeman EE, Ylli A, et al. Fear of falling and its association with life-space mobility of older adults: a crosssectional analysis using data from five international sites. Age Ageing [Internet]. 2017 [cited 2018 Nov 12];46(3):459-65. Available from: https:// academic.oup.com/ageing/article-lookup/doi/10.1093/ageing/afw239

36. Murata C, Kondo T, Tamakoshi K, Yatsuya H, Toyoshima H. Factors associated with life space among community-living rural elders in Japan. Public Health Nurs [Internet]. 2006;23(4):324-31. Available from: http://www. ncbi.nlm.nih.gov/pubmed/16817803.

37. Barnes LL, Wilson RS, Bienias JL, de Leon CFM, Kim H-JN, Buchman AS, et al. Correlates of life space in a volunteer cohort of older adults. Exp Aging Res [Internet]. 2007 [cited 2015 Jul 19];33(1):77-93. Available from: http://www. tandfonline.com/doi/abs/10.1080/03610730601006420\#.Vauma_khG40

38. Phillips J, Dal Grande E, Ritchie C, Abernethy AP, Currow DC. A populationbased cross-sectional study that defined normative population data for the Life-Space Mobility Assessment-composite score. J Pain Symptom Manage [Internet]. 2015 [cited 2016 Apr 27];49(5):885-93. Available from: https:// www.sciencedirect.com/science/article/pii/S0885392414005478

39. Cress ME, Orini $S$, Kinsler L. Living environment and mobility of older adults, Gerontology [Internet]. 2011 [cited 2014 Apr 2];57(3):287-94. Available from: http://www.ncbi.nlm.nih.gov/pubmed/20980733.

40. Rosso AL, Auchincloss AH, Michael YL. The urban built environment and mobility in older adults: a comprehensive review. J Aging Res [Internet]. 2011 [cited 2014 Apr 2];2011:816106. Available from: http://www. pubmedcentral.nih.gov/articlerender.fcgi?artid=3134204\&tool= pmcentrez\&rendertype $=$ abstract

41. Jones GR, Brandon C, Gill DP. Physical activity levels of community-dwelling older adults are influenced by winter weather variables. Arch Gerontol Geriatr [lnternet]. 2017 [cited 2017 Nov 28];71:28-33. Available from: http:// www.ncbi.nlm.nih.gov/pubmed/28258987.

42. Hoppmann CA, Lee JCM, Ziegelmann JP, Graf P, Khan KM, Ashe MC Precipitation and Physical Activity in Older Adults: The Moderating Role of Functional Mobility and Physical Activity Intentions. J Gerontol B Psychol Sci Soc Sci [Internet]. 2015 [cited 2016 Mar 13];gbv107. Available from: http:// psychsocgerontology.oxfordjournals.org/content/early/2015/12/25/geronb. gbv107.full

43. Portegijs E, Iwarsson S, Rantakokko M, Viljanen A, Rantanen T. Life-space mobility assessment in older people in Finland; measurement properties in winter and spring. BMC Res Notes [Internet]. 2014 [cited 2017 Jul 5];7(1):323. 
Available from: http://bmcresnotes.biomedcentral.com/articles/10.1186/1 756-0500-7-323

44. Umstattd Meyer MR, Janke MC, Beaujean A A. Predictors of Older Adults' Personal and Community Mobility: Using a Comprehensive Theoretical Mobility Framework. Gerontologist [Internet]. 2013 [cited 2014 Apr 2];gnt54: 1-11. Available from: http://www.ncbi.nlm.nih.gov/pubmed/23749391.

45. Kowalski K, Rhodes R, Naylor P-J, Tuokko H, MacDonald S. Direct and indirect measurement of physical activity in older adults: a systematic review of the literature. Int J Behav Nutr Phys Act [Internet]. 2012 [cited 2015 Jul 19];9(148). Available from: http://www.biomedcentral.com/content/ pdf/1479-5868-9-148.pdf

46. Murphy SL. Review of physical activity measurement using accelerometers in older adults: Considerations for research design and conduct. Prev Med (Baltim) [Internet]. 2009 [cited 2016 Mar 9];48(2):108-14. Available from: http://www.sciencedirect.com/science/article/pii/S0091743508006300

47. Ullrich $\mathrm{P}$, Eckert $\mathrm{T}$, Bongartz M, Werner $\mathrm{C}$, Kiss R, Bauer JM, et al. Life-space mobility in older persons with cognitive impairment after discharge from geriatric rehabilitation. Arch Gerontol Geriatr [Internet]. 2019 [cited 2019 Jan 15];81:192-200. Available from: https://www.sciencedirect.com/science/ article/abs/pii/S0167494318302395

48. Liddle J, Ireland D, McBride SJ, Brauer SG, Hall LM, Ding H, et al. Measuring the lifespace of people with Parkinson's disease using smartphones: proof of principle. JMIR mHealth uHealth [Internet]. 2014 [cited 2015 Aug 24];2(1): e13. Available from: http://www.pubmedcentral.nih.gov/articlerender. fcgi?artid=4114414\&tool $=$ pmcentrez\&rendertype $=$ abstract

49. Rantakokko M, Iwarsson S, Portegijs E, Viljanen A, Rantanen T. Associations between environmental characteristics and life-space Mobility in communitydwelling Older people. J Aging Health [Internet]. 2015;27(4):606-21 Available from: http://jah.sagepub.com/cgi/doi/10.1177/0898264314555328.

50. Tsai L-T, Rantakokko M, Rantanen T, Viljanen A, Kauppinen M, Portegijs E. Objectively Measured Physical Activity and Changes in Life-Space Mobility Among Older People. J Gerontol A Biol Sci Med Sci [Internet]. 2016 [cited 2016 Mar 29]; Available from: http://europepmc.org/abstract/med/26975981

51. Dawe RJ, Leurgans SE, Yang J, Bennett JM, Hausdorff JM, Lim AS, et al. Association between Quantitative Gait and Balance Measures and Total Daily Physical Activity in Community-Dwelling Older Adults. Journals Gerontol Ser A [Internet]. 2017 [cited 2017 Sep 6]; Available from: http:// academic.oup.com/biomedgerontology/article/doi/10.1093/gerona/gl×167/4 098337/Association-between-Quantitative-Gait-and-Balance

52. Owsley C. Visual Processing Impairment and Risk of Motor Vehicle Crash Among Older Adults. JAMA [Internet]. 1998 Apr 8 [cited 2015 Nov 4]; 279(14):1083. Available from: http://jama.jamanetwork.com/article. aspx?articleid=187414\&resultclick=1

53. Chigateri NG, Kerse N, Wheeler L, MacDonald B, Klenk J. Validation of an accelerometer for measurement of activity in frail older people. Gait Posture [Internet]. 2018 [cited 2018 Sep 3];66:114-7. Available from: https://www. sciencedirect.com/science/article/pii/S0966636218314383

54. Fillekes MP, Giannouli E, Kim E-K, Zijlstra W, Weibel R. Towards a comprehensive set of GPS-based indicators reflecting the multidimensional nature of daily mobility for applications in health and aging research. Int J Heal Geogr 2019181 [Internet]. 2019 Jul 24 [cited 2019 Jul 25];18(1):17. Available from: https://ij-healthgeographics.biomedcentral.com/articles/10.11 86/s12942-019-0181-0

55. Klenk J, Büchele G, Rapp K, Franke S, Peter R. Walking on sunshine: effect of weather conditions on physical activity in older people. J Epidemiol Community Health [Internet]. 2012 [cited 2014 Apr 13];66(5):474-6. Available from: http://www.ncbi.nlm.nih.gov/pubmed/21325149.

56. Salarian A, Horak FB, Zampieri C, Carlson-Kuhta P, Nutt JG, Aminian K. iTUG, a sensitive and reliable measure of mobility. IEEE Trans Neural Syst Rehabil Eng [Internet]. 2010 [cited 2014 May 4];18(3):303-10. Available from: http:// ieeexplore.ieee.org/articleDetails.jsp?arnumber $=5446357$

57. Dite W, Temple VA. A clinical test of stepping and change of direction to identify multiple falling older adults. Arch Phys Med Rehabil [Internet]. 2002 [cited 2017 Nov 28];83(11):1566-71. Available from: http://www.ncbi.nlm.nih. gov/pubmed/12422327.

58. Menzel-Begemann A. Handlungsorganisation und Tagesplanung: Testverfahren zur Erfassung der Planungsfähigkeit im Alltag. HOTAP: Hogrefe; 2010

59. Hüttermann S, Memmert D, Simons DJ, Bock O. Fixation strategy influences the ability to focus attention on two spatially separate objects. PLoS One. 2013;8(6):6-13.
60. Hale S, Myerson J, Rhee SH, Weiss CS, Abrams RA. Selective interference with the maintenance of location information in working memory. Neuropsychology. 1996;10(2):228-40.

61. Brickenkamp R. Test d2: Aufmerksamkeits-Belastungs-Test. Hogrefe Verlag für Psychologie; 2002.

62. Schott N. Deutsche Adaptation der "Activities-Specific Balance Confidence (ABC) Scale "zur Erfassung der sturzassoziierten Selbstwirksamkeit. Z Gerontol Geriatr [Internet]. 2008 Dec 30 [cited 2018 Aug 20];41(6):475-85. Available from: http://link.springer.com/10.1007/s00391-007-0504-9

63. Schwarzer R, Jerusalem M. The general self-efficacy scale (GSE). Anxiety Stress Coping. 2010;12(1):329-45.

64. Dias N, Kempen GIJM, Todd CJ, Beyer N, Freiberger E, Piot-Ziegler C, et al. Die Deutsche Version der Falls Efficacy Scale-International Version (FES-I). Z Gerontol Geriatr [Internet]. 2006 Aug [cited 2018 Aug 20];39(4):297-300. Available from: http://link.springer.com/10.1007/s00391-006-0400-8

65. Altmeier D, Kempe M, Memmert D. Stair self-efficacy questionnaire to test the ability of stair negotiation for older people. Ger J Exerc Sport Res [Internet]. 2018 [cited 2018 Mar 22];48(1):40-7. Available from: http://link. springer.com/10.1007/s12662-017-0483-y

66. Altmeier D, Giannouli E. German translation and psychometric properties of the modified Gait Efficacy Scale (mGES). Z Gerontol Geriatr. 2019;52(1).

67. Schmidt H. Mehrdimensionaler Persönlichkeitstest für Erwachsene. Hogrefe Verlag für Psychologie; 1981.

68. Russell DW. UCLA Loneliness Scale (Version 3): Reliability, Validity, and Factor Structure. J Pers Assess [Internet]. 1996 Feb [cited 2018 Dec 14];66(1):20-40. Available from: http://www.tandfonline.com/doi/abs/10.1207/s15327752 jpa6601_2

69. Yesavage JA, Brink TL, Rose TL, Lum O, Huang V, Adey M, et al. Development and validation of a geriatric depression screening scale: A preliminary report. J Psychiatr Res [Internet]. 1982 [cited 2018 Dec 14];17(1): 37-49. Available from: https://www.sciencedirect.com/science/article/pii/ 0022395682900334

70. Cohen S, Hoberman HM. Positive events and social supports as buffers of life change stress. J Appl Soc Psychol. 1983;13(2):99-125.

71. Palmore EB. Research Note: Ageism in Canada and the United States. J Cross Cult Gerontol [Internet]. 2004 Mar [cited 2018 Dec 14];19(1):41-6. Available from: http://link.springer.com/10.1023/B:JCCG.0000015098.62691.ab

72. Lubben JE. Assessing social networks among elderly populations. Fam Community Heal [Internet]. 1988 Nov [cited 2018 Dec 14];11(3):42-52. Available from: http://content.wkhealth.com/linkback/openurl?sid=WKPTLP: landingpage\&an=00003727-198811000-00008

73. Hoaglin DC, Iglewicz B, Tukey JW. Performance of Some Resistant Rules for Outlier Labeling. J Am Stat Assoc [Internet]. 2012 [cited 2015 Jul 17]; Available from: http://amstat.tandfonline.com/doi/abs/10.1080/01621459.1 986.10478363

74. Cohen J. Statistical power analysis for the behavioral sciences [Internet]. 1977 [cited 2019 Jan 16]. Available from: http://psycnet.apa.org/record/1 987-98267-000

75. Tsunoda K, Kitano N, Kai Y, Tsuji T, Soma Y, Jindo T, et al. Transportation mode usage and physical, mental and social functions in older Japanese adults. J Transp Heal [Internet]. 2015 Mar [cited 2015 Aug 26];2(1):44-9. Available from: http://www.sciencedirect.com/science/article/pii/S2214140514000875

76. Poranen-Clark T, von Bonsdorff MB, Rantakokko M, Portegijs E, Eronen J, Pynnönen $\mathrm{K}$, et al. The Temporal Association between Executive Function and Life-Space Mobility in Old Age. Journals Gerontol Ser A [Internet]. 2017 1 [cited 2017 Nov 7]; Available from: http://academic.oup.com/ biomedgerontology/article/doi/10.1093/gerona/gl×217/4584148

77. Snih S Al, Peek KM, Sawyer P, Markides KS, Allman RM, Ottenbacher KJ. LifeSpace Mobility in Mexican Americans Aged 75 and Older. J Am Geriatr Soc [Internet]. 2012 [cited 2018 Oct 27];60(3):532-7. Available from: http://doi. wiley.com/10.1111/j.1532-5415.2011.03822.x

78. Curcio C-L, Alvarado BE, Gomez F, Guerra R, Guralnik J, Zunzunegui MV. Life-Space Assessment scale to assess mobility: validation in Latin American older women and men. Aging Clin Exp Res [Internet]. 2013 [cited 2015 Aug 26];25(5):553-60. Available from: http://www.ncbi.nlm. nih.gov/pubmed/23949973.

79. Bauman AE, Reis RS, Sallis JF, Wells JC, Loos RJF, Martin BW. Correlates of physical activity: why are some people physically active and others not? Lancet [Internet]. 201221 [cited 2014 Jul 11];380(9838):258-71. Available from: http://www.sciencedirect.com/science/article/pii/S01406 73612607351 
80. Bandura A. Guide for constructing self-efficacy scales. In: Self-efficacy beliefs of adolescents; 2006. p. 307-37

81. Van Holle V, Van Cauwenberg J, De Bourdeaudhuij I, Deforche B, Van de Weghe N, Van Dyck D. Interactions between Neighborhood Social Environment and Walkability to Explain Belgian Older Adults' Physical Activity and Sedentary Time. Int J Environ Res Public Health [Internet]. 2016 Jun 7 [cited 2018 Jun 26];13(6):569. Available from: http://www.mdpi. com/1660-4601/13/6/569

82. Lachman ME, Weaver SL, Bandura M, Elliot E, Lewkowicz CJ. Improving Memory and Control Beliefs Through Cognitive Restructuring and Selfgenerated Strategies. J Gerontol [Internet]. 1992 [cited 2019 Mar 21];47(5): P293-9. Available from: https://academic.oup.com/geronj/article-lookup/ doi/10.1093/geronj/47.5.P293

\section{Publisher's Note}

Springer Nature remains neutral with regard to jurisdictional claims in published maps and institutional affiliations.

Ready to submit your research? Choose BMC and benefit from:

- fast, convenient online submission

- thorough peer review by experienced researchers in your field

- rapid publication on acceptance

- support for research data, including large and complex data types

- gold Open Access which fosters wider collaboration and increased citations

- maximum visibility for your research: over $100 \mathrm{M}$ website views per year

At $\mathrm{BMC}$, research is always in progress.

Learn more biomedcentral.com/submissions 